\title{
Katil Mayalar ve Williopsis spp.'nin Bozucu Mikroorganizmalar Üzerindeki Etkisi, Katil Toksinlerin Kullanım Olanakları
}

\author{
Arzu KAVAZ YÜKSEL ${ }^{1}$, Mehmet YÜKSEL*2 (D) \\ ${ }^{1}$ Atatürk Üniversitesi, Erzurum Meslek Yüksekokulu, Gıda Teknolojisi Bölümü, 25240 Erzurum, Türkiye \\ ${ }^{2}$ Atatürk Üniversitesi, Hınıs Meslek Yüksekokulu, Gıda Teknolojisi Bölümü, Hınıs, Erzurum, Türkiye
}

Geliş / Received: 16/06/2018, Kabul / Accepted: 26/11/2018

\section{$\ddot{O} z$}

Bazı maya türleri, bulundukları ortama protein yapısında olan ve diğer mikroorganizmalar üzerinde öldürücü etki gösteren toksinler salgılarlar. Bu mayaların ürettiği toksinler, aynı türün suşlarına veya yakın ilişkili türlere karşı inhibisyon aktivitesi gösteren protein yapısındaki bileşiklerdir; ancak diğer mikroorganizmalara ve insan hücrelerine karşı herhangi bir olumsuz etkileri yoktur. Bugüne kadar öldürücü toksin üreten maya türleri, genel olarak çok çeşitli maya grupları içinde tanımlanmıştır. İlk olarak katil toksin özelliğinin Saccharomyces cerevisiae suşlarında belirlenmesinin ardından, bu özellik Debaryomyces, Hanseniaspora, Kluyveromyces, Pichia, Saccharomyces, Schwanniomyces and Williopsis cinslerinin de içinde bulunduğu 90'dan fazla maya türü için tespit edilmiştir. Bunlar içinde Williopsis'in tür ve suşları en iyi bilinen katil toksin üreticileridir. Katil mayaların gıda sektöründe kullanılması birçok araştırmaya konu olmuştur ve elde edilen sonuçlar ile katil mayaların biyoteknoloji, biyomedikal ve fermentasyon uygulamalarında biyokoruyucu olarak kullanımının uygun olabileceği ortaya konulmuştur. Bu derleme çalışmasında bazı katil mayalar ve ürettikleri toksinlerin bozucu mikroorganizmalar üzerindeki etkisi ve kullanım olanakları hakkında bilgi verilmeye çalışılmıştır.

Anahtar Kelimeler: Mayalar, Biyokoruma, Williopsis, katil toksin, bozucu mikroorganizmalar

\section{Effects of Killer Yeasts and Williopsis spp. on the Spoilage Microorganisms and Application Posibilities of Killer Toxsins}

\begin{abstract}
Abctract
Some yeast strains secrete protein based extracellular toxins into the medium that that have a killing effect on other microorganisms. The toxins produced by these yeasts are compounds in the structure of proteins which exhibit inhibitory activity against the same strain or closely related species, but they have not any negative effects on other microorganisms and human cells. Until now, yeast species producing lethal toxin have been generally described in a wide variety of yeast groups. Firstly, after the discovery of the killer phenomenon in strains of Saccharomyces cerevisiae, this property has been determined in more than 90 yeast species including Debaryomyces, Hanseniaspora, Kluyveromyces, Pichia, Saccharomyces, Schwanniomyces and Williopsis. Among these, the species and strains of Williopsis are the best known killer toxin producers. The application of killer yeasts in the food industry has been the subject of many investigations ve the obtained results revealed that the use of killer yeasts as bioprotective agents in biotechnology, biomedical and fermentation applications may be appropriate. In this review study, some killer yeasts and toxins that are produced by them have been tried to be informed about the effects on the microorganisms and their possibilities of use. In this review study, some killer yeasts and their toxins have been tried to be given information about the effects on the microorganisms and their possibilities of use.
\end{abstract}

Keywords: Yeasts, Biopreservation, Williopsis, killer toxin, spoilage microorganisms

\section{Giriş}

Mayalar, insanlar ve hayvanlar tarafindan tüketilen pek çok fermantasyon ürünü gıda üzerinde olumlu veya olumsuz bir takım etkilere sahip olabilmektedir. $\mathrm{Bu}$ mikroorganizmalar, peynir ve ekmeğin yanı sıra şarap, bira ve diğer fermantasyon ürünlerinde starter kültür olarak kullanılmaktadır; ancak yoğurt, meyve suyu, salatalar ve mayonez gibi gidalardaki bozulmalara da neden olabilmektedirler. Mayalar, farklı koşullarda gelişme ve hayatta 
kalma özelliği ve çok çeşitli çevresel ve beşeri ekosistemlerde kolonileşme yeteneği ile karakterize edilen büyük bir mikroorganizma grubunu oluşturmaktadır. Diğer mikroorganizmalara karş1 rekabet özellikleri, mayaların tarım, gıda ve tıbbi sektörlerde biyokoruyucu ajan olarak başarılı bir şekilde kullanımlarına olanak sağlamıştır (Muccilli and Restuccia, 2015).

Bazı maya türleri, bulundukları ortama protein yapısında olan ve diğer mikroorganizmalar (örneğin mayalar ve küfler) üzerinde antagonistik etki gösteren katil toksin olarak adlandirılan bir takım öldürücü maddeler salgılarlar (Suzzi Vd., 1995; Izgu and Altinbay, 1997; Magliani Vd., 1997). Katil toksinler doğal bir protein olup düşük pH'da aktiftirler ve bunlar, hücrenin plazma membranına salınan, bölünen ve aktif olmayan glikosile edilmiş formda üretilirler (Zhu Vd., 1993; Becker Vd., 2018).

1960'1 y1llarda Bevan and Makover (1963) tarafindan Saccharomyces cerevisiae suşlarındaki katil olgunun keşfedilmesinin ardından, öldürücü aktivite ve birkaç katil proteininin özelliği, Debaryomyces, Hanseniaspora, Kluyveromyces, Pichia, Saccharomyces, Schwanniomyces ve Williopsis cinslerininde içinde olduğu 90'dan fazla maya türü için belirlenmeye çalış1lmıştır (Golubev, 1998, Chen Vd., 2000; Morales-Menchén Vd., 2018). Bugüne kadar toksin üreten bu tür katil mayalar, yaygın bir şekilde Candida, Cryptococcus, Debaryomyces, Hanseniaspora, Hansenula, Kluyveromyces, Metschnikowia, Pichia, Saccharomyces, Ustilago, Torulopsis, Williopsis, Mrakia ve Zygosaccharomyces cinsleri içinde tanımlanmıştır (Magliani Vd., 1997). Bunlar içinde en çok incelenen katil maylar, toksinleri RNA ve DNA plazmid koduna sahip olan $S$. cerevisiae ve Kluyveromyces lactis'tir (Stark Vd., 1990; Bussey, 1991; Naumova Vd., 2017). Williopsis, Pichia, Candida, Debaryomyces,
Cryptococcus ve Torulopsis suşları için karakterize edilen katil maya özelliğinin plazmid kodlu sistemlere bağımlı olduğuna dair henüz bir kanıt bulunamamıştır (Young ve Yagui, 1978). Bu nedenle, bu mayalardaki katil karakterinin genetik temelinin, kromozomal olarak bir geçiş göstermiş olabileceği düşünülmektedir (Ashida Vd., 1983)

Mayalar, öldürücü karakter bakımından, nötral, duyarlı ve öldürücü olmak üzere 3 farklı fenotipik özellik göstermektedir. Katil suşlar, hassas suşları öldüren hücre dış1 bir toksin üretirken, kendileri bu toksinlere karşı bağışıklık kazanmışlardır. Buna karşın nötral suşlar katil toksin üretmezler ya da öldürücü özellik göstermezler (Bussey, 1972). Bu mayaların ürettiği öldürücü toksinler, aynı türün üyelerine veya yakından ilişkili türlere karşı aktif olan proteinli bileşiklerdir. Bu yönüyle bakteriyel türler tarafindan üretilen bakteriyosinlerin aktivitelerine benzer bir özellik göstermektedirler. $\mathrm{Bu}$ toksinler uygun koşullar altında küfler ve bazı duyarlı maya türlerine karşı antagonistik yani öldürücü bir etki göstermektedir ancak; diğer mikroorganizmalara ve insan hücrelerine karşı bu yönde zararlı veya öldürücü herhangi bir etkileri tespit edilememiştir. Bunun nedeni katil toksinlerin sadece belirli hücre duvarı materyallerine etkili olmaları ve bazı özel hücre duvarı bileşenlerine duyarlılık göstermeleridir. Katil toksin mekanizması, toksinden toksine göre farklılık gösterebilir; çünkü bu özellik çift zincirli RNA, linear çift zincirli DNA veya kromozom üzerinde kodlanmış olabilmektedir (Magliani Vd., 1997; Schaffrath Vd., 2017; Schaffrath Vd.,2018).

Katil mayaların gıda sektöründe kullanılması birçok araştırmaya konu olmuştur ve alınan sonuçlar katil mayaların biyoteknoloji, biyomedikal ve fermentasyon uygulamalarında koruyucu olarak kullanımının umut verici olabileceğini ortaya 
koymuştur (Türkay, 2012; Schaffrath Vd., 2018). Çünkü; gelişen teknoloji gereği gidalarda patojen ve bozucu mikroorganizmaların gelişimini inhibe eden maddelerin kullanımın gerekliliği ortaya çıkmış ve genel olarak, bu inhibe edici maddelerin, bitkilerden, hayvanlardan ve mikroorganizmalardan elde edilmesi oldukça yaygınlık kazanmıştır (Chessa Vd., 2017). Örneğin; sütten elde edilen laktoperoksidaz, yumurta beyazı ve incirden elde edilen lizozim, bitkiler ve baharatlardan elde edilen saponinler ve flavonoidler, laktik asit bakterilerinden elde edilen bakteriosinler ve bitkilerden elde edilen ve uçucu yağları kapsayan bazı antimikrobiyal bileşikler yaygın bir şekilde gida sanayinde kullanılmaktadır (Tiwari Vd., 2009; Lucera Vd., 2012). Mikroorganizmalar tarafindan üretilen doğal antimikrobiyal maddeler ve özellikle de bakteri kökenli olanların antimikrobiyal aktiviteleri genel olarak tanımlanmış olmasına rağmen, maya kökenli olanlar ile ilgili çok fazla araştırma yapılmamıştır ((Tiwari Vd., 2009; Hatoum Vd., 2012).

\section{Mayaların}

antimikrobiyal

aktivitesinde yer alan farklı mekanizmalar arasında, katil toksinlerin salgılanması en az 40 yıldır araştırılmaktadır. Çok çeşitli cins ve türlere ait birçok yabani veya kültür suşu mayaların katil toksin üretebildikleri rapor edilmiştir. Bu toksinler, genetik belirleyiciler, biyokimyasal özellikler ve etki mekanizmaları açısından büyük biyoçeşitlilik ile karakterize edilen proteinler veya glikoproteinlerdir. $\mathrm{Bu}$ toksinlerin ikinci önemli özelliği ise, hücre membranının permeabilizasyonu yoluyla iyon sizıntısı meydana getirmesi, tRNA'ların bölünmesi ve G1'de translasyonel bir y1kım oluşturması, $25 \mathrm{~s}$ ve 18 s rRNA'nın parçalanmasına neden olması, DNA sentezinin inhibisyonu, $\beta$-1,3glukan sentez aktivitesinin inhibisyonu ve ağır hücre duvarı hasarı gibi etkiler göstermeleridir (Chen Vd., 2000; De Ingeniis Vd., 2009).

Katil maya suşlarının araştırılmasıyla elde edilen sonuçlar, Pichia ve Williopsis cinsi baz1 spor yapic1 ascomycetes cinsi mayaların, Candida spp. ve Sacchammyces cerevisiae cinsi hassas maya suşlarına karşı en geniş aktivite sergilediğini ortaya koymuştur Farklı cinslere ait katil türler; toksik bileşen üretimi, $\mathrm{pH}$, sıcaklık stabilitesi ve proteolitik enzimlere karşı duyarlılık gibi parametreler dikkate alınarak sınıflandırılmıştır (Hodgson Vd., 1995; Banjara Vd., 2016).

\section{Katil Mayalar ve Bu Mayalardaki Öldürücü Yapının Genetik Temeli}

Katil fenotipik ekspresyonunun genetik temeli oldukça değişken olabilir. Katil belirleyicilerin açıkça tanımlandığı durumlar, ya sitoplazmik temelli kapsüllenmiş çift sarmallı RNA (dsRNA), ya da linear dsDNA plazmidleri veya kromozomal genlerdir. Katil toksinlerin genetik temelleri, yapısı, spesifik reseptörleri ve araştırılan birçok maya öldürücü sistemin tanınmış etki mekanizmaları Tablo 1 ve Tablo 2'de özetlenmiştir 
Tablo 1. En çok araştırılan mayalardaki katil olgunun genetik temeli (Magliani Vd., 1997; Jijakli ve Lepoivre, 1998; Guyard Vd., 2002; Schmitt ve Breinig, 2002; Izgu ve Altinbay, 2004; Santos Vd., 2009; Ochigava Vd., 2011)

\begin{tabular}{|c|c|c|c|c|}
\hline Genetik Temel & Toksin Üreten Maya & $\begin{array}{l}\text { Toksin } \\
\text { Geninin } \\
\text { Adı }\end{array}$ & $\begin{array}{l}\text { Toksin } \\
\text { Geninin } \\
\text { Boyutu } \\
\text { (Kbp) }\end{array}$ & $\begin{array}{l}\text { Öldürücü } \\
\text { Toksinin } \\
\text { Adı }\end{array}$ \\
\hline \multirow{5}{*}{$\begin{array}{l}\text { Sitoplazmada kalıtsal } \\
\text { olarak kapsüllenmiş } \\
\text { çift sarmallı RNA } \\
\text { (dsRNA) }\end{array}$} & $\begin{array}{l}\text { Saccharomyces } \\
\text { cerevisiae }\end{array}$ & $\begin{array}{l}\text { M1 } \\
\text { M2 } \\
\text { M28 }\end{array}$ & $\begin{array}{l}1.8 \\
1.5 \\
1.9\end{array}$ & $\begin{array}{l}\text { K1 } \\
\text { K2 } \\
\text { K28 }\end{array}$ \\
\hline & Ustilago maydis & $\begin{array}{l}\mathrm{M} 1 / \mathrm{M} 2 \\
\mathrm{M} 2 \\
\mathrm{M} 2\end{array}$ & $\begin{array}{l}1.4 \\
0.98 \\
1.2 \\
\end{array}$ & $\begin{array}{l}\text { P1 } \\
\text { P4 } \\
\text { P6 }\end{array}$ \\
\hline & $\begin{array}{l}\text { Hanseniaspora } \\
\text { uvarum }\end{array}$ & M & - & - \\
\hline & Phaffia rhodozyma & $\mathrm{M}$ & - & - \\
\hline & $\begin{array}{l}\text { Zygosaccharomyces } \\
\text { bailii }\end{array}$ & M & - & - \\
\hline \multirow[t]{3}{*}{$\begin{array}{l}\text { Linear çift iplikçikli } \\
\text { plazmidler }\end{array}$} & Kluyveromyces lactis & $\begin{array}{l}\text { pGkL } 1 \\
\text { pGkL } 2\end{array}$ & $\begin{array}{l}8.8 \\
13.4\end{array}$ & $\begin{array}{l}- \\
-\end{array}$ \\
\hline & Pichia acaciae & $\begin{array}{l}\text { pPac } 1-1 \\
\text { pPac } 1-2\end{array}$ & $\begin{array}{l}13.6 \\
6.8 \\
\end{array}$ & $\begin{array}{l}- \\
-\end{array}$ \\
\hline & Pichia inositovora & $\begin{array}{l}\text { pPin 1-1 } \\
\text { pPin 1-3 }\end{array}$ & $\begin{array}{l}18 \\
10\end{array}$ & - \\
\hline \multirow[t]{6}{*}{ Kromozomal genler } & $\begin{array}{l}\text { Saccharomyces } \\
\text { cerevisiae }\end{array}$ & $\begin{array}{l}\text { KHR } \\
\text { KHR }\end{array}$ & $\begin{array}{l}0.9 \\
2.1\end{array}$ & $\begin{array}{l}\text { KHR } \\
\text { KHR }\end{array}$ \\
\hline & Pichia farinosa & SMK1 & 0.6 & KK1 \\
\hline & $\begin{array}{l}\text { Pichia } \\
\text { membranifaciens }\end{array}$ & $\begin{array}{l}- \\
-\end{array}$ & $\begin{array}{l}- \\
-\end{array}$ & $\begin{array}{l}\text { PMKT } \\
\text { PMKT }\end{array}$ \\
\hline & Willioposis mrakii & HMK & - & $\begin{array}{l}\mathrm{HM}-1, \quad \mathrm{~K}- \\
500\end{array}$ \\
\hline & Williopsis saturnus & HSK & - & HSK \\
\hline & $\begin{array}{ll}\text { Williopsis } & \text { saturnus } \\
\text { var. mrakii } & \\
\end{array}$ & - & - & WmkT \\
\hline
\end{tabular}

Tablo 2. Katil toksinler, yapıları, büyüklükleri spesifik reseptörleri ve en çok araştırılan mayaların katil mekanizması (Magliani Vd., 1997, Jijakli ve Lepoivre, 1998, Guyard Vd., 2002, Schmitt ve Breinig, 2002, Izgu ve Altinbay, 2004, Santos Vd., 2009, Ochigava Vd., 2011)

\begin{tabular}{|c|c|c|c|c|c|}
\hline Maya Kültürü & $\begin{array}{c}\text { Öldürücü } \\
\text { Toksinin } \\
\text { adı }\end{array}$ & $\begin{array}{c}\text { Öldürücü } \\
\text { Toksinin } \\
\text { yapısı }\end{array}$ & $\begin{array}{c}\text { Öldürücü } \\
\text { Toksin } \\
\text { Boyutu } \\
\text { (KDa) }\end{array}$ & Reseptör & $\begin{array}{c}\text { Etki } \\
\text { mekanizması }\end{array}$ \\
\hline \multirow{3}{*}{$\begin{array}{l}\text { Saccharomyces } \\
\text { cerevisiae }\end{array}$} & $\mathrm{K} 1$ & $\alpha \beta$ dimer & 19.0 & \multirow{2}{*}{$\begin{array}{ll}\beta-1,6 & D- \\
\text { glukan } & \end{array}$} & \multirow{2}{*}{$\begin{array}{l}\text { Memebranda } \\
\text { iyonlara karşı } \\
\text { geçirgenlikteki } \\
\text { artış }\end{array}$} \\
\hline & $\mathrm{K} 2$ & $\alpha \beta$ dimer & 21.5 & & \\
\hline & K28 & $\alpha \beta$ dimer & 21.5 & $\alpha-1,3-$ & DNA sentezinin \\
\hline
\end{tabular}




\begin{tabular}{|c|c|c|c|c|c|}
\hline & & & & mannoprotein & inhibisyonu \\
\hline \multirow[t]{3}{*}{ Ustilago maydis } & $\mathrm{P} 1$ & $\alpha \beta$ dimer & 19.0 & - & \multirow{3}{*}{$\begin{array}{l}\text { Memebranda } \\
\text { iyonlara karş1 } \\
\text { geçirgenlikteki } \\
\text { artış }\end{array}$} \\
\hline & $\mathrm{P} 2$ & Monomer & 11.1 & - & \\
\hline & P6 & $\alpha \beta$ dimer & 17.7 & - & \\
\hline $\begin{array}{l}\text { Kluyveromyces } \\
\text { lactis }\end{array}$ & - & $\begin{array}{l}\alpha \beta \gamma \text { trimer } \\
156.5\end{array}$ & 156.5 & Kitin & \multirow{2}{*}{$\begin{array}{l}\text { G1 Hücre } \\
\text { döngüsünün } \\
\text { durdurulmas1, } \\
\text { kitinaz aktivitesi }\end{array}$} \\
\hline Pichia acaciae & - & Trimer & $\sim 190$ & Kitin & \\
\hline \multirow{2}{*}{$\begin{array}{l}\text { Saccharomyces } \\
\text { cerevisiae }\end{array}$} & KHR & Monomer & 20 & - & \multirow{2}{*}{$\begin{array}{l}\text { Memebranda } \\
\text { iyonlara karşı } \\
\text { geçirgenlikteki } \\
\text { artış }\end{array}$} \\
\hline & KHS & Monomer & 75 & - & \\
\hline $\begin{array}{l}\text { Pichia anomala } \\
\text { WC65 }\end{array}$ & - & Monomer & 83.3 & $\begin{array}{ll}\beta-1,6 & \mathrm{D}- \\
\text { glukan } & \end{array}$ & - \\
\hline $\begin{array}{l}\text { Pichia anomala } \\
\text { NCYC434 }\end{array}$ & K5 & - & 49 & $\begin{array}{l}\beta-1,3 \quad \mathrm{D}- \\
\text { glukan }\end{array}$ & Glukanaz \\
\hline $\begin{array}{l}\text { Pichia } \\
\text { farinosa }\end{array}$ & SMK1 & $\alpha \beta$ dimer & 14.2 & - & $\begin{array}{l}\text { Memebranda } \\
\text { iyonlara karşı } \\
\text { geçirgenlikteki } \\
\text { artış }\end{array}$ \\
\hline $\begin{array}{l}\text { Pichia } \\
\text { Kluyveri }\end{array}$ & - & Monomer & 19 & - & $\begin{array}{l}\text { Memebranda } \\
\text { iyonlara karşı } \\
\text { geçirgenlikteki } \\
\text { artış }\end{array}$ \\
\hline \multirow[t]{2}{*}{$\begin{array}{l}\text { Pichia } \\
\text { membranifaciens }\end{array}$} & PMKT & - & - & $\begin{array}{l}\beta \quad-1,6 \quad \mathrm{D}- \\
\text { glukan }\end{array}$ & - \\
\hline & PMKT2 & - & 30 & mannoprotein & - \\
\hline $\begin{array}{l}\text { Schwanniomyces } \\
\text { occidentalis }\end{array}$ & & Dimer & $7.4-4.9$ & Mannan & - \\
\hline \multirow[t]{2}{*}{ Williopsis mrakii } & HM-1 & Monomer & 10.7 & $\begin{array}{l}\text { Hücre duvarı } \\
\beta \text { - glukan }\end{array}$ & $\begin{array}{l}\beta 1,3 \text { glukan } \\
\text { sentezinin } \\
\text { inhibisyonu }\end{array}$ \\
\hline & $\begin{array}{l}\mathrm{K}- \\
500\end{array}$ & Monomer & $1.8-5$ & $\begin{array}{l}\text { Hücre duvarı } \\
\beta \text { - glukan }\end{array}$ & $\begin{array}{l}\text { Memebranda } \\
\text { iyonlara karşı } \\
\text { geçirgenlikteki } \\
\text { artış }\end{array}$ \\
\hline $\begin{array}{l}\text { Williopsis } \\
\text { saturnus } \\
\text { mrakii }\end{array}$ & WmkT & Monomer & 85 & $\begin{array}{l}\text { Hücre duvarı } \\
\beta \text {-glukan }\end{array}$ & $\begin{array}{l}\text { Glukanaz } \\
\text { aktivitesi }\end{array}$ \\
\hline
\end{tabular}

\subsection{Katil Bir Maya Williopsis spp.}

Williopsis spp. gıda ile ilişkili olan ve patojen olmayan bir mayadir (Wyder ve Puhan, 1999; Seiller, 2002; Ciafardini Vd., 2006). Birkaç Williopsis spp. türü mikojeniktir ve diğer mayalara karşı antagonistik bir özellik göstermektedir (Michalcakova Vd., 1993; Vital Vd., 2002).
Mikojenik aktivite, Williopsis cinsi (eski adıyla Hansenula) içinde yer alan $W$. saturnus var. saturnus, $W$. saturnus var. mrakii, W. saturnus var. subsufficiens, W. californica ve W. beijerinckii türleri arasında oldukça yaygın bir olgudur (Nomoto Vd., 1984; Michalcakova Vd., 1993; Vital Vd., 2002). Bu mayaların geniş bir anti maya aktivitesine sahip oldukları ancak küflerin 
gelişimini engelleyemedikleri bildirilmiştir (Yamamoto Vd., 1988). Williopsis'in ürettiği mikosinlerden gıda, yem ve tıp alanında, mayalardan kaynaklanabilecek bozulmaların önlenmesi için ve mayalardan kaynaklanan enfeksiyonlarının tedavisinde yararlanılmaktadır (Hodgson Vd., 1995; Lowes Vd., 2000). Williopsis cinsi mayalar arasında bu konuda en çok dikkat çekenler, W. saturnus var. saturnus ve $W$. saturnus var. mrakii'dir. $\mathrm{Bu}$ iki mayanın öldürücü spektrumu benzerlik göstermektedir. Mikosinlerinin amino asit dizilimleri, yapısal benzerlikleri bakımından oldukça geniş bir homolojiye sahiptir (Kimura Vd., 1993). Williopsis tarafından sentezlenen mikosinler, mayaların hücre duvarının glukan sentezine müdahale ederek hücrenin duvar sentezini bozar ve bu şekilde mayayı inhibe eder (Takasuka Vd., 1995; Guyard Vd., 2002).

\subsubsection{Williopsis (Hansenula) mrakii, Williopsis saturnus ve Williopsis saturnus var. mrakii}

Williopsis cinsinin tür ve suşları içinde yer alan $W$. saturnus var. saturnus ve $W$. saturnus var. mrakii en çok bilinen katil toksin üreticileridir (Michalcakova Vd., 1993; Liu ve Tsao, 2009). Bu mayalar ayrica aroma ve lezzet oluşumundaki potansiyelleri ve alkollü içecek fermantasyonu için kullanımları bakımından da pek çok araştırmaya konu olmuşlardır (Inoue Vd., 1994; Erten ve Campbell, 2001; Yilmaztekin Vd., 2008, 2009).

Williopsis mrakii ve Williopsis saturnus'a ait toksinler kromozomal gen temelinde kodlanmışlardır. Williopsis saturnus'a ait toksin geninin araştırmaları henüz sonuç vermese de Williopsis mrakii'ye ait en az iki farklı katil toksin tanımlanmıștır: İlk olarak 1983'te tanımlanan toksin HMK veya HM-1 olarak adlandırılmış ve ikincisi ise daha yakın zamanda tanımlanmış ve K500 olarak isimlendirilmiștir (Hodgson Vd.,1995; Altuntaş ve Özçelik, 2007). Bu toksinler, yüksek termal aktivite ve $\mathrm{pH}$ stabilitesi göstermekte ve diğer mayalara karşı geniş bir antimikrobiyal aktivite spektrumu sergilemektedir.

Williopsis mrakii'nin katil suşlarından biri LKB 169 (5 NCYC 2251) geniş aktivite spekturumuna sahip iki mikosin üretmektedir (Ashida Vd., 1983; Barnett Vd., 1990). Bunların ürettiği toksinlerden biri olan HMK veya $\mathrm{HM}-1,88$ amino asitten $(10.721 \mathrm{kDa})$ oluşan glikosilatlanmış temel bir polipeptiddir (Hodgson Vd., 1995, Magliani Vd., 1997). Bu amino asitlerden 10'u sisteinden oluşmaktadır. Bu proteinin yapısı oldukça basittir ve asidik özellik gösterme eğiliminde olan diğer mikosinlerin aksine $\mathrm{pH}$ 9.1'lik bir izoelektrik noktaya ve $10.7 \mathrm{kDa}$ 'lık bir moleküler kütleye sahiptir. Ayrıca, oldukça termostabil olup, $100{ }^{\circ} \mathrm{C}^{\prime} \mathrm{de} \quad 10$ dakikalık bir sürede biyolojik aktivitesini ve $\mathrm{pH}$ 2-11 değerleri arasında ise stabilitesini korumaktadır. HMK, $\beta$-merkaptoetanol gibi indirgeyici ajanlar tarafindan engellenir ve yüksek bir $\mathrm{pH}$ değerinde kaynatılarak inaktive edilir. HMK, hücrenin $\beta-1,3$ glukan sentezine müdahale eder ve hücre duvarını osmotik olarak kırılgan hale getirir ve sağlam hücreleri öldürür. Böylece hücrenin lizisi gerçekleşir ve hücre ölümü meydana gelir (Takasuka Vd., 1995). Geniş aktivite spektrumu, $\mathrm{pH}$ stabilitesi ve sicaklık kararlılığı nedeniyle, W. mrakii tarafından üretilen HMK mikosininin bir dizi gida ve yem sisteminde çok yönlü bir anti bozulma ajanı olarak kullanılabileceğini ortaya koymuştur. HM-1, $\beta$-1, 3-D-glukan sentezinin in vitro aktivitesini inhibe eder. Bu toksin, tomurcuklanma alanlarındaki glukan sentezini veya bağlama tüplerini inhibe ederek maya hücre duvarının sentezini engeller ve bu da hücrenin lizisine sebep olur (Hodgson Vd., 1995, Magliani Vd.,1997). K500 öldürücü toksini ise, 1.8 ve $5.0 \mathrm{kDa}$ arasında bir moleküler kütleye sahip asidik bir polipeptiddir. Yüksek sicaklık ve $\mathrm{pH}$ değerlerinin 4.0'ün üstüne çıkması 
durumunda kolayca inaktif olur. Bu toksin geniş bir anti-Candida aktivitesine sahiptir. Ancak, bu toksin henüz tam anlamıyla karakterize edilmemiştir ve öldürme mekanizması ise belirsizliğini korumaktadır (Hodgson Vd., 1995; Magliani Vd., 1997; Liu Vd., 2015).

W. saturnus, W. mrakii tarafindan üretilen HMK'ya benzerlik gösteren HSK toksini üretmektedir. $\mathrm{Bu}$ toksinin öldürücü özelliğinin moleküler mekanizmasının muhtemelen diğer toksinlerle aynı olduğu düşünülmektedir (Kimura Vd., 1993).

\section{Gıda Güvenliğini Sağlamada Mayaların Kullanım Potansiyelleri}

Kimyasal gida koruyucuları, yaygın olarak gıdaların raf ömrünü uzatmak ve bozulmaya neden olan mikroorganizmalar ile patojen bakterilerin gelişimini engelleyerek gıdaların güvenirliğini artırmak için kullanılmaktadır. Bununla birlikte, halk sağlığı açısından doğrudan bir risk oluşturan potansiyel toksisite ve antimikrobiyal maddelere dirençli patojenlere yönelik artan tüketici bilinci, biyolojik korumanın olası bir alternatif olarak değerlendirilmesini sağlamış ve uzmanları bu konudaki yöntemleri araştırmaya yöneltmiştir (Ross Vd., 2002; Carocho Vd., 2015).

Biyolojik koruma veya biyo-kontrol, raf ömrünü uzatmak ve gida güvenliğini artırmak için doğal ve kontrollü mikroorganizmaların veya bu mikroorganizmaların ürettiği antimikrobiyal ürünlerinin kullanımını ifade eder. Bu; üretici suşun kendisi olmadan antimikrobiyal metabolitlerinin eklenmesini, gida kalitesini etkilemeyen antimikrobiyal metabolitler üreten bir kültür ilavesini veya koruyucu etkileri barındıran pro-teknolojik mikroorganizmaların kullanımını kapsamaktadır (Stiles, 2014).

Bir takım mikroorganizmalar ve diğer biyolojik ajanlar, gidaların muhafaza edilmesinde dolaylı olarak ( $\mathrm{pH}$ veya ozmotik basıncı değiştirmek suretiyle) veya direkt olarak (toksik bileşikler, antimikrobiyal bileşenler, enzimler ve antibiyotikler vb. üretmek suretiyle) bir biyolojik koruma faktörü olarak kabul görmüştür. Mikroorganizmaların antagonistik özellikleri üzerinde en yoğun çalışmalar ve pratik uygulamalar laktik asit bakterilerine odaklanmış olmasına rağmen; son yirmi yıldaki çalışmalar daha çok doğal kaynaklı mayaların gida kaynaklı bakterilerin, mayaların ve küflerin gelişimi üzerindeki etkilerine yönelik yapılmıştır (Galvez Vd., 2014; Chi Vd., 2010; Liu Vd., 2013).

Mayalardan antimikrobiyal ajanlar, diğer mikroorganizmalardan sağlananlara göre daha kolay elde edilmektedir. Çünkü; birçok maya türü basit beslenme gereksinimine sahiptir ve uzun süreler boyunca kuru yüzeylere kolonize edilebilir ve biyolojik reaktörlerde uygun özelliklere sahip ucuz substratlarda hızla geliştirilebilir ve ürettikleri metabolitler kolaylıkla ortamdan alınabilir (Chanchaichaovivat Vd., 2007).

\section{Mayaların}

Antagonistik

\section{Karakteristikleri}

Mayalar tarafindan salgilanan toksinlerin diğer mayalara karşı gösterdikleri antagonistik etkiler şunlardır: Üretilen toksinlerin diğer mayaları öldürmesi veya gelişimini engellemesi, katil toksinin hücre duvarına bağlanması, transmembran kanalların oluşumunu sağlaması, iyon sızıntısına neden olması, hedef hücredeki transkripsiyon veya replikasyon mekanizmasını bozması, hassas suşların hücre duvarında $\beta$-glukan sentezinin inhibisyonu veya $\beta$-glukanın hidrolizi, DNA sentezinin bloke edilerek hücre bölünmesinin durdurulması, tRNA'nın bölünmesinin engellenmesi, kalsiyum alımının bloke edilmesi, hücre zarı fonksiyonunu veya hücre duvarı sentezinin inhibisyonu, besin 
maddelerine karşı yarışma, mayaların gelişimi sonucunda oluşan organik asitlerin besi ortamının pH'sını değiştirmesi, yüksek konsantrasyonlarda etanol üretimi ve antibakteriyal bileşiklerin sekrasyonu (örneğin öldürücü toksinler veya mikosinler) ve en nihayetinde hücrenin ölümüne neden olması şeklinde meydana gelmektedir (Young ve Yagiu, 1978; Suzuki Vd., 2001; Klassen ve Meinhardt, 2005; Magliani Vd., 2008).

Mikosinler, eksatraselüler protein veya glikoprotein yapısında diğer bozucu mayaların hücre duvarını parçalama özelliğine sahip toksinlerdir. Ancak; bu tür katil toksinler, hücre duvarı olmayan hayvan ve insan hücreleri üzerinde herhangi bir etkiye sahip değillerdir. (Golubev, 2006). Mikosinler, ilk olarak bira endüstrisinde kullanılan Saccharomyces türlerinde tespit edilmiş ve daha sonra Candida, Cryptococcus, Debaryomyces, Kluyveromyces, Pichia, Torulopsis, Williopsis ve Zygosaccharomyces türü mayalar tarafından da üretildiği belirlenmiştir (Young ve Yagiu, 1978; Magliani Vd., 1997; Chen Vd., 2000; Schmitt ve Breinig, 2002; Golubev, 2006; Banjara Vd., 2016; Lu Vd., 2017). Genetik çalışmalar, öldürücü toksinlerin, çift iplikçikli RNA virüsü formundaki ekstra kromozamal elementler üzerinde taşındığını ortaya koymuştur. Katil toksinler protein yapılıdır. Genellikle düşük pH optimizasyonuna sahiptir ve yüksek sıcaklıklarda kolaylıkla inaktif hale gelir. Bu ortak özelliklere rağmen katil toksinlerin özellikleri türler ve suşlar arasında farklılık gösterebilir (Woods ve Bevan, 1968; Lu Vd., 2017).

\subsection{Katil Mayalarm Bakteriler Üzerindeki Etkisi}

Çok sayıda öldürücü toksin üreten mayanın antagonistik özelliğinden sadece bozucu mayaların inhibisyonunda değil aynı zamanda küf ve bakterilerin gelişiminin önlenmesinde de yararlanılmaktadır (Michalcakova Vd., 1993). Bir araştırmada, Hansenula anomala, Williopsis mrakii, Kluyveromyces drosophylarum, Kluyveromyces lactis ve Candida tropicalis türlerinin Gram pozitif patojenik ve patojenik olmayan bakterilerin gelişimini inhibe edici bir özelliğe sahip olduğu ortaya konulmuştur (Ochigava Vd., 2011). Başka bir araştırmada baz1 mikosinlerin, Staphylococcus aureus başta olmak üzere bazı patojenik Gram pozitif bakteriler üzerinde inhibe edici etkilere sahip olduğu tespit edilmiştir (Izgu ve Altinbay, 1997).

\subsection{Katil Toksinlerin Gıda Üretiminde ve Çeşitli Uygulamalardaki Avantaj ve Riskleri}

İstenmeyen mikroorganizma olarak belirlenen bazı katil mayalar gidalarda bozulmalara ve çeşitli risklere neden olabilmektedir. Buna karşıllk genetik ilerlemeler ve rekombinant DNA teknolojisi ve ilerleyen monoklonal antikor (antibody) çalışmaları ile genetik materyalde yapılan katil özellik düzenlemeleri sayesinde, bilim adamları zararlı koşullar altında bile katil mayaların faydalı etkilerini kullanmanın mümkün olabileceğini rapor etmişlerdir. Son yirmi yılda, katil toksinler ve toksini üreten katil mayalar etki mekanizmalarına bağlı olarak farklı alanlarda kullanılmaya başlanmıştır. Örneğin; gıda ve fermantasyon endüstrisinde, özellikle de şarap, bira ve ekmek üretimi sırasında ortaya çıkabilen bulaşıcı tip yabani mayaların gelişimini sınırlandırmak için katil mayalar kullanılmaktadir. $\mathrm{Bu}$ mayalar, gidaların korunmasında, tıbben önemli patojenik mayaların ve maya benzeri mantarların biyolojik olarak kontrolünde, insan ve bitki mantar enfeksiyonlarının tedavisinde, yeni antimikotiklerin geliştirilmesinde biyolojik kontrol ajanı olarak kullanılmaktadır (Chi Vd., 2010; El-Banna Vd., 2011). Bozucu mayalar üzerinde aktif olarak etki gösteren 
bazı katil toksinler, fermantasyon, gida ve yem endüstrileri için ilgi çekici doğal antimikrobiyal maddeler olarak değerlendirilebilmektedir (Lowes Vd., 2000; Todd Vd., 2000; Ciani ve Fatichenti, 2001). Bazı durumlarda, katil mayanın fermantasyonda starter kültür olarak doğrudan inoküle edilmesinin, bozucu mayalarının gelişimini engellediği ve istenmeyen bazı metabolik aktivitelerin oluşumunu önlediği öne sürülmüştür. Başka bir uygulama ise, katil bir suşun düşük miktarda toksin üretmesi ve/veya zayıf fermentatif özellik göstermesi durumunda saflaştırılmış katil toksinin kullanılması şeklinde olabilmektedir (Zagorc Vd., 2001; Liu ve Tsao, 2009; Ciani ve Comitini, 2011; Liu Vd., 2015).

\subsection{Katil Mayaların Gida ve Fermantasyon Endüstrisinde Kullanımı}

Gıda bozulmaları, ürünleri tüketici için kabul edilemez bir hale getirdiğinden gida endüstrisi için ciddi bir sorundur. Pek çok mikroorganizma gibi birçok bozucu maya da, iyi imalat prosedürleri uygulanmadığı zaman ürünlerde gelişebilmekte ve sorunlara neden olabilmektedir. $\mathrm{Bu}$ durum, zayıf fabrika hijyeni, eksik veya yetersiz koruyucular, yetersiz pastörizasyon sicaklığı ve/veya düşük kaliteli hammadde kullanımından kaynaklanmaktadır ve ekonomik kayıplara, potansiyel sağlık risklerine neden olabilmektedir (Fleet, 1992; Viljoen Vd., 2003; Stratford, 2006). Bu nedenle gidaların bozulmasının önlenmesi için gıdalarda kullanıma uygun antimikrobiyal bileşikler, özellikle sorbik ve benzoik asit türevleri kullanılabilmektedir. Bununla birlikte, bazı bozucu mayaların da birçok kimyasal koruyucuya karşı direnç gösterdiği tespit edilmiştir (Battey Vd., 2002; Papadimitriou Vd., 2007).

\section{G1da} endüstrisi,

bozucu mikroorganizmalardan ve patojenlerden korunmak için katil toksin üreten mayaların kullanımını ilk keşfeden endüstriler arasında yer almaktadır (Lowes Vd., 2000). Genel olarak, şarap, sosis, süt ürünleri üretimi ve firıncılık gibi endüstrilerde bozucu mikroorganizmaların gelişimini engellemek için kullanılmaktadır. Mayalar, işlenmiş gıdalar ve içeceklerin üretimindeki rollerine ilave olarak, işlenmemiş gıdalardaki bozulmaları da engeller veya toksin üreten mikroorganizmaları çeşitli mekanizmalarla antagonize eder (Du Toit ve Pretorius, 2000; Sperber ve Doyle, 2009). Alternatif bir yaklaşım olarak, gıdalardaki istenmeyen mikroorganizmaların aktivitelerini engelleyebilen seçilmiş mayalar ve/veya üretilen katil proteinlerin kullanılması gida sektörü için son derece önemli bir buluştur.

\subsection{Katil Mayaların Potansiyel Antimikrobiyal Ajan Olarak Kullanımı}

Son zamanlarda yapılan çalışmalar, mayalar tarafından üretilen öldürücü toksinlerin antifungal ajan olarak kullanımına odaklanmıştır (Schmitt ve Breinig, 2002). Katil maya olgusu, maya katil toksinlerinin, insan ve hayvanlarda görülen fungal ve bakteriyel kaynaklı enfeksiyonlara karş1 geniş spektrumdaki etkinlikleri nedeniyle ilgi uyandırmaktadır (Polonelli Vd., 1986; Yamamoto Vd., 1988, Walker Vd., 1995). Ayrıca; bazı mayaların, bitki patojeni funguslara karş1 biyolojik kontrol ajanı olarak kullanılma potansiyelleri de vardır. Pichia membranifaciens, gri küf hastalığına neden olan Botrytis cineria'yı kontrol etme potansiyeline sahiptir (Santos et.al., 2004; Khorjuvenkar Vd., 2016).

Mayaların öldürücü aktivitesi bakteriler üzerinde de değerlendirilmiş ve alkol fermantasyonunda kontamine olan bakterilerin biyo kontrolünde kullanılabildiği gösterilmiştir (Polonelli ve Morace, 1986; Meneghin Vd., 2010). Örneğin; Candida glabrata ve Pichia anomala'dan elde edilen toksinlerin, Lactobacillus plantarum ve Bacillus subtilis'e karşı aktif olduğu tespit 
edilmiştir (Polonelli ve Morace, 1986). Fermente edilmiş sebzelerden izole edilen Candida kruseii'nin katil toksinin, Escherichia coli, Staphylococcus aureus, Salmonella typhimurum ve Bacillus cereus'a karş1 bir inhibisyon gösterdiği saptanmıştır (Waema Vd., 2009). Yine Saccharomyces cerevisiae'ya ait katil toksinin bakteri suşlarına karşı olan katil etkinliği Meneghin Vd. (2010) ve OrentaiteVd. (2016) tarafindan rapor edilmiştir. Bununla birlikte, Williopsis saturnus var. mrakii NCYC500'ten K9 katil toksinin Streptococcus penumoniae üzerindeki öldürücü etkisi yakın zamanda Ochigava Vd. (2011) tarafindan bildirilmiştir.

\section{Sonuç}

Mayalar, sahip oldukları katil toksinler nedeniyle diğer mikroorganizmalarla rekabet edebilecek güçlü bir mikroorganizma grubunu oluşturmaktadır. Katil maya türleri, moleküler karakteristikleri, genetik belirleyiciler, etki spektrumu ve ürettikleri toksinlerin etki mekanizması bakımından geniş bir biyolojik çeşitliliğe sahiptirler. Bununla birlikte, bugüne kadar bilinen katil toksinlerin sadece küçük bir kısmı ayrıntılı olarak karakterize edilebilmiştir. Diğer maya türlerinde de bilinmeyen başka toksik mekanizmanın veya katil toksinlerin ortaya çıkma ihtimali, bilinen katil toksinlerin gıda endüstrisinde biyolojik koruyucu olarak daha yaygın bir şekilde kullanılma olasılığını artırmaktadır. Ayrica, katil toksinlerin konvansiyonel ilaçlara karşı dirençli mikrobiyal enfeksiyonların tedavisi için farmasötik ve tıbbi sektörlerde de uygulama alanı bulmasıyla yeni nesil antimikrobiyal ajanların geliştirilmesi, önümüzdeki dönemde bu konunun daha fazla araştırılmasına imkan sağlayacaktır.

\section{Kaynaklar}

Altuntaş, G. E., Özçelik, F. (2007). Killer özellikli mayaların etki mekanizmaları ve endüstride yol açtıkları sorunlar. Glda, 32, :205-212.

Ashida, S., Shimazaki, T., Kitano, K., Hara, S. (1983). New killer toxin of Hansenula mrakii. Agricultural and Biological Chemistry, 47(12), 29532955.

Banjara, N., Nickerson, K.W., Suhr, M.J., Hallen-Adams, H.E. 2016. Killer toxin from several food-derived Debaryomyces hansenii strains effective against pathogenic Candida yeasts. International journal of food microbiology, 222, 23-29.

Barnett, J. A., Payne, R. W., Yarrow, D. (1990). "Yeasts: Characteristics and identification", 2nd ed. Cambridge University Press, Cambridge, United Kingdom.

Battey, A. S., Duffy, S., Schaffner, D. W. (2002). Modeling yeast spoilage in cold-filled readyto- drink beverages with Saccharomyces cerevisiae, Zygosaccharomyces bailii, and Candida lipolytica. Applied and Environmental Microbiology, 68, 1901-1906.

Becker, B., Schmitt, M.J. 2018. Correction: Becker, B. et al. Yeast Killer Toxin K28: Biology and Unique Strategy of Host Cell Intoxication and Killing. Toxins, 10(4), 132.

Bevan, E. A., Makover, M. (1963). The physiological basis of the killer character in yeasts (Geerts, S.J., Ed.), Genetic Today, XIth International Congress on Genetics, vol. 1, pp. 202-203. Pergamon Press, Oxford.

Bussey, H. (1972). Effects of the yeast killer factor on sensitive cells. Nature: New Biology, 235, 73-75.

Bussey, H. (1991). K1 killer toxin, a poreforming protein from yeast. Molecular Microbiology, 5, 2339-2343. 
Carocho, M., Morales, P., Ferreira, I. C. (2015). Natural food additives: Quo vadis? Trends in Food Science and Technology, 45(2), 284-295.

Chanchaichaovivat, A., Ruenwongsa, P., Panijpan, B. (2007). Screening and identification of yeast strains from fruits and vegetables: potential for biological control of postharvest chilli anthracnose (Colletotrichum capsici). Biological Control, 42, 326-335.

Chen, W. B., Han, Y. F., Jong, S. C., Chang, S. C. (2000). Isolation, purification, and characterization of a killer protein from Schwanniomyces occidentalis. Applied and Environmental Microbiology, 66, 5348-5352.

Chessa, R., Landolfo, S., Ciani, M., Budroni, M., Zara, S., Ustun, M., Cakar, Z. P., Mannazzu I. (2017). Biotechnological exploitation of Tetrapisispora phaffii killer toxin: heterologous production in Komagataella phaffii (Pichia pastoris). Applied Microbiology and Biotechnology, 101, 2931--2942.

Chi, Z. M., Liu, G.L., Zhao, S. F., Li, J., Peng, Y. (2010). Marine yeasts as biocontrol agents and producers of bioproducts. Applied Microbiology and Biotechnology, 86, 1227--1241.

Ciafardini, G., Zullo, B.A., Cioccia, G., Iride, A. (2006). Lipolytic activity of Williopsis californica and Saccharomyces serevisiae in extra virgin olive oil, International Journal of Food Microbiology, 107, 27-32.

Ciani, M., Comitini, F. (2011). NonSaccharomyces wine yeasts have a promising role in biotechnological approaches to winemaking. Annals of Microbiology, 61, 25-32.

Ciani, M., Fatichenti, F. (2001). Killer toxin of Kluyveromyces phaffii DBVPG 6076 as a biopreservative agent to control apiculate wine yeast. Applied and Environmental Microbiology, 67, 3058-3063.
De Ingeniis, J., Raffaelli, N., Ciani, M., Mannazzu, I. (2009). Pichia anomala DBVPG 3003 secretes a ubiquitin-like protein that has antimicrobial activity. Applied and Environmental Microbiology, 75(4), 1129-1134.

Du Toit, M., Pretorius, I. S. (2000). Microbial spoilage and preservation of wine: using weapons from nature's own arsenal-a review. South African Journal for Enology and Viticulture, 21, 74-96.

El-Banna, A. A., Malak, A. E., Shehata, M. G. (2011).Yeasts producing killer toxins: An overview. Alexandria Journal of Food Science and Technology, 8(2), 41-53.

Erten, H., Campbell, I. (2001). The production of low-alcohol wines by aerobic yeasts, Journal of the Institute of Brewing, 107, 207-215.

Fleet, G. H., (1992). Spoilage yeasts. Critical Review of Biotechnology, 12, 1-44.

Galvez, A., Grande Burgos, M. J., López, R. L., Perez Pulido, R. (2014). "Food Biopreservation", Springer-Verlag, New York, NY, USA, 15-22.

Golubev, W. I. (1998). "Mycocins (killer toxins), The yeasts", A taxonomic study. Elsevier, Amsterdam, The Netherlands, 55-62.

Golubev, W.I. (2006). Antagonistic interactions among yeasts. Biodiversity and ecophysiology of yeasts, SpringerVerlag, Berlin, Germany, 197--219.

Guyard , C. , Dehecq , E., Tissier , J., Polonelli , L., Dei-Cas , E., Cailliez , J., Menozzi , F. D. (2002). Involvement of $\beta$-glucans in the widespectrum antimicrobial activity of Williopsis saturnus var. mrakii MUCL 41968 killer toxin. Molecular Medicine, 8, 686-694.

Hatoum, R., Labrie, S., Fliss, I. (2012). Antimicrobial and probiotic properties of yeasts: from fundamental to novel 
applications. Frontiers

Microbiology, 3, 421.

Hodgson, V. J., Button, D., Walker, G. M. (1995). Anti-Candida activity of a novel killer toxin from the yeast Williopsis mrakii. Microbiology, 141(8), 2003-2012.

Inoue, Y., Fukuda, K., Wakai, Y., Sudsai, T., Kimura, A. (1994). Ester formation by a yeast Hansenula mraki IFO 0895: Contribution of esterase for iso-amyl acetate production in sake brewing, Lebensmittel-Wissenshaft und Technologie, 27, 189-93.

Izgu, F., Altinbay, D. (1997). Killer toxins of certain yeast strains have potential growth inhibitory activity on Grampositive pathogenic bacteria. Microbios, 89, 15-22.

Izgu, F., Altinbay, D. (2004). Isolation and characterization of the K5-type yeast killer protein and its homology with an exo- $\beta$-1,3-glucanase. Bioscience Biotechnology and Biochemistry, 68, 685-693.

Jijakli, M. H., Lepoivre, P. (1998). Characterization of an exo- $\beta-1, \quad 3-$ glucanase produced by Pichia anomala strain K, antagonist of Botrytis cinerea on apples. Phytopathology, 88(4), 335343.

Khorjuvenkar, S N.P., Doijad, S.P., Poharkar, K., Dubal, Z.B., Barbuddhe, S.B. 2016. Antimicrobial Activity of a Novel Pichia membranifaciens Strain Isolated from Naturally Fermented Cashew Apple Juice. Proceedings of the National Academy of Sciences, India Section B: Biological Sciences, 86(1), 125-129.

Kimura, T., Kitamoto, N., Matsuoka, K., Nakamura, K., Iimura,Y., Kito, Y. (1993). Isolation and nucleotide sequences of the genes encoding killer toxins from Hansenula mrakii and $H$. saturnus. Gene, 137, 265-270. in Klassen, R., Meinhardt., F. (2005). Induction of DNA damage and apoptosis in Saccharomyces cerevisiae by a yeast killer toxin. Cellular Microbiology, 7(3), 393-401.

Liu, G.L., Chi, Z., Wang, G.Y., Wang, Z.P., Li, Y., Chi, Z.M. 2015. Yeast killer toxins, molecular mechanisms of their action and their applications. Critical reviews in biotechnology, 35(2), 222234.

Liu, J., Sui, Y., Wisniewski, M., Droby, S., Liu, Y. (2013). Review: Utilization of antagonistic yeasts to manage postharvest fungal diseases of fruit. International Journal of Food Microbiology. 167, 153-160.

Liu, S. Q., Tsao, M. (2009). Inhibition of spoilage yeasts in cheese by killer yeast Williopsis saturnus var. saturnus. International Journal of Food Microbiology, 131(2-3), 280-282.

Lowes, K., Shearmen, C. A., Payne, J., Mackenzie, D., Archa, D. B., Merry, R. J., Gasson, M. J. (2000). Preventation of yeast spoilage in feed and food by the yeast mycocins HMK. Applied and Environmental Microbiology, 66, 1066-1076.

Lu, Y., Peh, J.C.H., Lee, P.R., Liu, S.Q. 2017. Modulation of grape wine flavor via the sequential inoculation of Williopsis saturnus and Saccharomyces cerevisiae. Food Biotechnology, 31(4), 245-263.

Lucera, A., Costa, C., Conte, A., Del Nobile, M. A. (2012). Food applications of natural antimicrobial compounds. Frontiers in Microbiology, 3, 287.

Magliani, W., Conti, S., Gerloni, M., Bertolotti, D., Polonelli, L. (1997). Yeast killer systems. Clinical Microbiology Reviews, 10, 369-400.

Magliani, W., Conti, S., Travassos, L. R., Polonelli, L. (2008). From yeast killer toxins to antibiobodies and beyond. 
FEMS Microbiology letters, 288 (1), 18.

Meneghin, M. C., Reis, V. R., CeccatoAntonini, S. R. (2010). Inhibition of bacteria contaminating alcoholic fermentations by killer yeasts. Brazilian Archives of Biology and Technology, 53, 1043-1050.

Michalcakova, S., Sulo, P., Slavikova, E. (1993). Killer yeasts of Kluyveromyces and Hansenula genera with potential application in fermentation and therapy. Acta Biotechnology, 13, 34150.

Morales-Menchén, A., Navarro-García, F., Guirao-Abad, J.P., Román, E., Prieto, D., Coman, I.V., Alonso-Monge, R. 2018. Non-canonical activities of Hog 1 control sensitivity of Candida albicans to killer toxins from Debaryomyces hansenii. Frontiers in cellular and infection microbiology, 8, 135.

Muccilli, S., Restuccia, C. (2015). Bioprotective role of yeasts. Microorganisms 3(4), 588-611.

Naumova, E.S., Lee, C.F., Kondratieva, V.I., Sadykova, A.Z., Naumov, G. I. 2017. Molecular genetic polymorphism of soil yeasts of the genus Williopsis from Taiwan Island. Russian Journal of Genetics, 53(5), 561-567.

Nomoto, H., Kitano, K., Shimazaki, T., Kodama, K., Hara, S. (19844). Distribution of killer yeasts in the genera Hansenula. Agricultural and Biological Chemistry, 48, 807-809.

Ochigava, I., Collier, P. J., Walker, G. M., Hakenbeck, R. (2011). Williopsis saturnus yeast killer toxin does not kill Streptococcus pneumonia. Antonie van Leeuwenhoek, 99, 559-566.

Orentaite, I., Poranen, M.M., Oksanen, H.M., Daugelavicius, R., Bamford, D.H. 2016. K2 killer toxin-induced physiological changes in the yeast Saccharomyces cerevisiae. FEMS yeast research, 16(2).
Papadimitriou, M. N. B., Resende, C., Kuchler, K., Brul, S. (2007). High Pdr12 levels in spoilage yeast (Saccharomyces cerevisiae) correlate directly with sorbic acid levels in the culture medium but are not sufficient to provide cells with acquired resistance to the food preservative. International Journal of Food Microbiology, 113, 173-179.

Polonelli, L., Lorenzini, R., de Bernardis, F., Morace, G. (1986). Potential therapeutic effect of yeast killer toxin. Mycopathologia, 96, 103-107.

Polonelli, L., Morace, G. (1986). Reevaluation of the yeast killer phenomenon. Journal of Clinical Microbiology, 24, 866-869.

Ross, R. P., Morgan, S., Hill, C. (2002). Preservation and fermentation: Past, present and future. International Journal of Food Microbiology, 2002, 79, 3-16.

Santos, A., San Mauro, M., Bravo, E., Marquina, D. (2009). PMKT2, a new killer toxin from Pichia membranifaciens, and its promising biotechnological properties for control of the spoilage yeast Brettanomyces bruxellensis, Microbiology, 155, 624634.

Santos, A., Sanchez, A., Marquira, D. (2004).Yeast as biological agent to control Botrytis cinerae. Microbiological Rsearch, 159, 331339.

Schaffrath, R., Mehlgarten, C., Prochaska, H., Hammermeister, A., Abdel-Fattah, W., Wagner, M., Krutyhołowa, R., Jun, S.E., Kim, G., Glatt, S., Breunig, K.D., Stark, M.J. 2017. Use of a Yeast TRNase Killer Toxin to Diagnose Kti12 Motifs Required for TRNA Modification by Elongator. Preprints, 2017080001.

Schaffrath, R., Meinhardt, F., Klassen R. 2018. Yeast Killer Toxins: 
Fundamentals and Applications. In: Anke T., Schüffler A. (eds) Physiology and Genetics. The Mycota (A Comprehensive Treatise on Fungi as Experimental Systems for Basic and Applied Research), vol 15. Springer, Cham

Schmitt, M.. J., Breinig, F. (2002). The viral killer system in yeast: from molecular biology to application. FEMS Microbiology Reviews, 26, 257-276.

Seiller, H. 2(2002). Yeasts in milk and dairy products, Encyclopedia of Dairy Science, Academic Press, New York, 4, 2761-2769.

Sperber, W. H. Doyle, M. P. (2009). Compendium of the Microbiological Spoilage of Foods and Beverages; Springer, New York, USA.

Stark, M. J. R., Boyd, A., Mileham, A. J., Romanos, M. A. (1990). The plasmidencoded killer system of Klyveromyces lactis. Yeast, 6, 1-29.

Stiles, M. E. (1996). Biopreservation by lactic acid bacteria. Antonie van Leeuwen, 70, 331-345.

Stratford, M. (2006). Food and beverage spoilage yeasts. Yeasts in Food and Beverage, Springer, Berlin, 335-379.

Suzuki, C., Ando,Y., Machida, S. (2001). Interaction of SMKT, a killer toxin produced by Pichiafarinosa, with the yeast cell membranes. Yeast 8, 14711478 .

Suzzi, G., Romano, P., Ponti, I., Montuschi, C. (1995). Natural wine yeasts as biocontrol agents, Journal of Applied Bacteriology, 78, 304-308.

Takasuka, T., Komiyama, T., Furuchi, Y., Watanabe, T. 1(1995). Cell wall synthesis specific cytocidal effect of Hansenula mraki toxin-1 on Saccharomyces cerevisiae, Cellular and Molecular Biology Research, 41,Vol. 41, pp. 575-81.
Tiwari, B. K., Valdramidis, V. P., O'Donnell, C. P., Muthukumarappan, K., Bourke, P., Cullen, P. J. (2009). Application of natural antimicrobials for food preservation. Journal of Agricultural and Food Chemistry, 57 (14), 59876000 .

Todd, B. E. N, Fleet, G. H., Henschke, P. A. (2000). Promotion of autolysis through the interaction of killer and sensitive yeasts: potential application in sparkling wine production. American Journal of Enology and Viticulture, 51, 65-72.

Türkay, Ç. (2012). Katil maya Lindnera saturnus' un bozucu mayalara etkisi (in vitro). Namık Kemal Üniversitesi Fen Bilimleri Enstitüsü. Yüksek Lisans Tezi, 2012, 56.

Viljoen, B. C., Lourens-Hattingha, A., Ikalafenga, B., Peter, G. (2003). Temperature abuse initiating yeast growth in yoghurt. Food Research International, 36, 193-197.

Vital, M. J. S., Abranches, J., Hagler, A. N., Mendoca-Hagler, L. C. (2002). Mycocinogenic yeasts isolated from Amazon soils of the Maraca Ecological Station, Rorainma. Brazilian Journal of Microbiology, 33, 230-235.

Waema , S., Maneesri, J., Masniyom, P. (2009). Isolation and identification of killer yeast from fermented Vegetables. Asian Journal of Food and AgroIndustry, 2, 126-134.

Walker, G. M., Mcleod, A. H., Hodgson, V. J. (1995). Interactions between killer yeasts and pathogenic fungi. FEMS Microbiology Letters, 127, 213-222.

Woods, D. R., Bevan, E. A. (1968). Studies on the Nature of the killer factor produced by Saccharomyces cerevisiae. Journal of General Microbiology, 51(1), 115-126.

Wyder, M. T., Puhan, Z. (1999). Role of selected yeasts in cheese ripening: an evaluation in aseptic cheese curd 
slurries. International Dairy Journal, 9, 11724.

Yamamoto, T., Uchida, K., and Hiratani, T. (1988). In vitro activity of the killer toxin from yeast Hanenula maraki against yeasts and moulds. Journal of Antibiotics, 41, 398-403.

Yilmaztekin, M., Erten, H., Cabaroglu, T. (2008). Production of isoamyl acetate from sugar beet molasses by Williopsis saturnus var. saturnus. Journal of the Institute of Brewing, 114, 34-38.

Yilmaztekin, M., Erten, H., Cabaroglu, T. (2009.) Enhanced production of isoamyl acetate from beet molasses with addition of fusel oil by Williopsis saturnus var. saturnus. Food Chemistry, 112, 290-294.

Young, T. W., Yagiu, M. (1978). A comparison of the killer character in different yeasts and its classification. Antonie van Leeuwenhoek, 44, 59-77.

Zagorc, T., Maraz, A., Cadez, N., Jemec, K. P., Peter, G., Resnik, M., Nemanic, J., Raspor, P. (2001). Indigenous wine killer yeasts and their application as a starter culture in wine fermentation. Food Microbiology, 18, 441-451.

Zhu, Y. S., Kane, J., Zhang, X. Y., Zhang, M., Tipper. D. J. (1993). Role of the gamma component of preprotoxin in expression of the yeast $\mathrm{k} 1$ killer phenotype. Yeast, 9, 251-266. 